\title{
The Incidence of Stent-edge Spasm After Stent Implantation in Patients With or Without Vasospastic Angina Pectoris
}

\author{
Bunji KAKU, ${ }^{1}$ MD Kanaya HonIn, ${ }^{1}$ MD, Yhuki Horita, ${ }^{1}$ MD, \\ Yoshihide UNO, ${ }^{1} \mathrm{MD}$, Tsukasa YAMAZAKI, ${ }^{1} \mathrm{MD}$, Akira FunADA, ${ }^{1} \mathrm{MD}$, \\ and Takio OHKA, ${ }^{1} \mathrm{MD}$
}

\begin{abstract}
SUMMARY
Although several investigations have reported that stent implantation is an option for the treatment of vasospastic angina (VSA) that is resistant to medical treatment, we are concerned about the occurrence of new stent-edge spasms after stenting. The purpose of this study was to determine the incidence of new stent-edge spasms after stenting. Twenty-seven patients with VSA and 23 patients without VSA were enrolled. About 6 months after stent implantaion, a spasm provocation test was performed by intracoronary infusion of acetylcholine or ergonovine in 26 patients with VSA and all patients without VSA, and the induced stent-edge spasms were classified as either moderate (stent-edge spasm $>75 \%$ and $<95 \%$ reduction in coronary artery diameter) or severe (stent-edge spasm $>95 \%$ reduction in coronary artery diameter). In one patient with VSA, stent-edge spasm and acute thrombosis occurred several hours after stent implantation. The remaining 26 patients with VSA had no complications during or after stent implantation. However, during the chronic phase, severe stent-edge spasm was provoked in 5 patients with VSA (19.2\%) and in 2 patients without VSA (8.7\%). Moderate stent-edge spasm was provoked in 5 patients with VSA (19.2\%) and 5 patients without VSA (21.7\%). The results suggest new onset stent-edge spasm in patients either with or without VSA should not be neglected. (Int Heart J 2005; 46: 23-33)
\end{abstract}

Key words: Coronary stent, Coronary spasm, Vasospastic angina, Stent-edge spasm

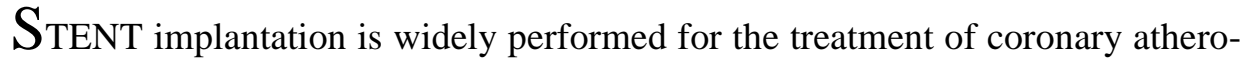
sclerosis and its usefulness has been confirmed by several investigators. ${ }^{1,2}$ In addition several studies have reported that stent implantation is an option for the treatment of coronary vasospastic angina (VSA) that is resistant to adequate medical treatment. ${ }^{3-9)}$ On the other hand, Muroya, et $a l^{10)}$ reported that stent implantation can induce severe stent-edge spasm in patients without coronary spasm

From the ${ }^{1}$ Division of Cardiology, Department of Internal Medicine, Ishikawa Prefectural Central Hospital, Kanazawa, Japan.

Address for correspondence: Bunji Kaku, MD, Department of Internal Medicine, Ishikawa Prefectural Central Hospital, Kuratsuki Higashi 2-1, Kanazawa, Ishikawa 920-8530, Japan.

Received for publication January 6, 2004.

Revised and accepted August 5, 2004. 
before stent implantation. In this situation, the following questions arise. Does stent-edge spasm newly occur after stent implantation in patients with highly vasospastic activity? Does stent-edge spasm newly occur in patients who did not have coronary spasm before stenting? Should medical treatment of coronary spasm be discontinued after stenting of the spastic lesion? Therefore, in daily clinical practice, it is unclear whether stent implantation is truly safe in patients with VSA, and what the incidence is of newly occurring stent-edge spasm in patients with or without VSA. The purpose of this study was to determine complications during stent implantation in patients with VSA and the incidence of stent-edge spasm occurring after stent implantation.

\section{Methods}

Patients: Twenty-seven patients with VSA who did not have stent restenosis (>75\% diameter stenosis) at the stent implanted site were enrolled in this study [24 males, 3 females; age, $63 \pm 9$ (mean \pm SD)]. The diagnosis of VSA was based on previously reported criteria (rest angina, induction of total or subtotal spasm, and ischemic electrocardiographic change during spasm provocation test). ${ }^{11)}$ In these patients, coronary stent implantation was performed as the treatment of organic stenotic lesions $>75 \%$ diameter stenosis. We did not perform stent implantation for the treatment of coronary spasm itself in any of the patients with VSA. In the VSA group, stent implantation was undertaken to treat acute myocardial infarction in 11 patients and angina pectoris in 16 patients. Twenty-three patients without VSA who did not have stent restenosis (>75\% diameter stenosis) at the stent implanted site were also enrolled [18 males, 5 females; age, $63 \pm 12$ (mean $\pm \mathrm{SD}$ )]. None of these 23 patients had symptoms such as rest angina suggesting coronary spasm and we confirmed that coronary spasm $>75 \%$ reduction in coronary artery diameter was not induced during the spasm provocation test, except for the stent edge. In the non-VSA group, stent implantation was conducted to treat acute myocardial infarction in 13 patients and angina pectoris in 10 patients.

The details are described in Tables I and II.

Spasm provocation test: Spasm provocation testing was performed by intracoronary infusion of acetylcholine or ergonovine in 26 patients with VSA and all patients without VSA $6.4 \pm 2.0$ months after coronary stent implantation. Acetylcholine chloride (Daiichi Pharmaceutical) was injected into the left coronary artery in incremental doses of 20,50 , and $100 \mu \mathrm{g}$ over 30 seconds or into the right coronary artery in incremental doses of 20 and $50 \mu \mathrm{g}$ over 30 seconds. Ergometrine malate (Fuji Pharmaceutical) was injected into the left or right coronary artery in incremental doses of 10 and $40 \mu$ g over 4 minutes. In the VSA group, 


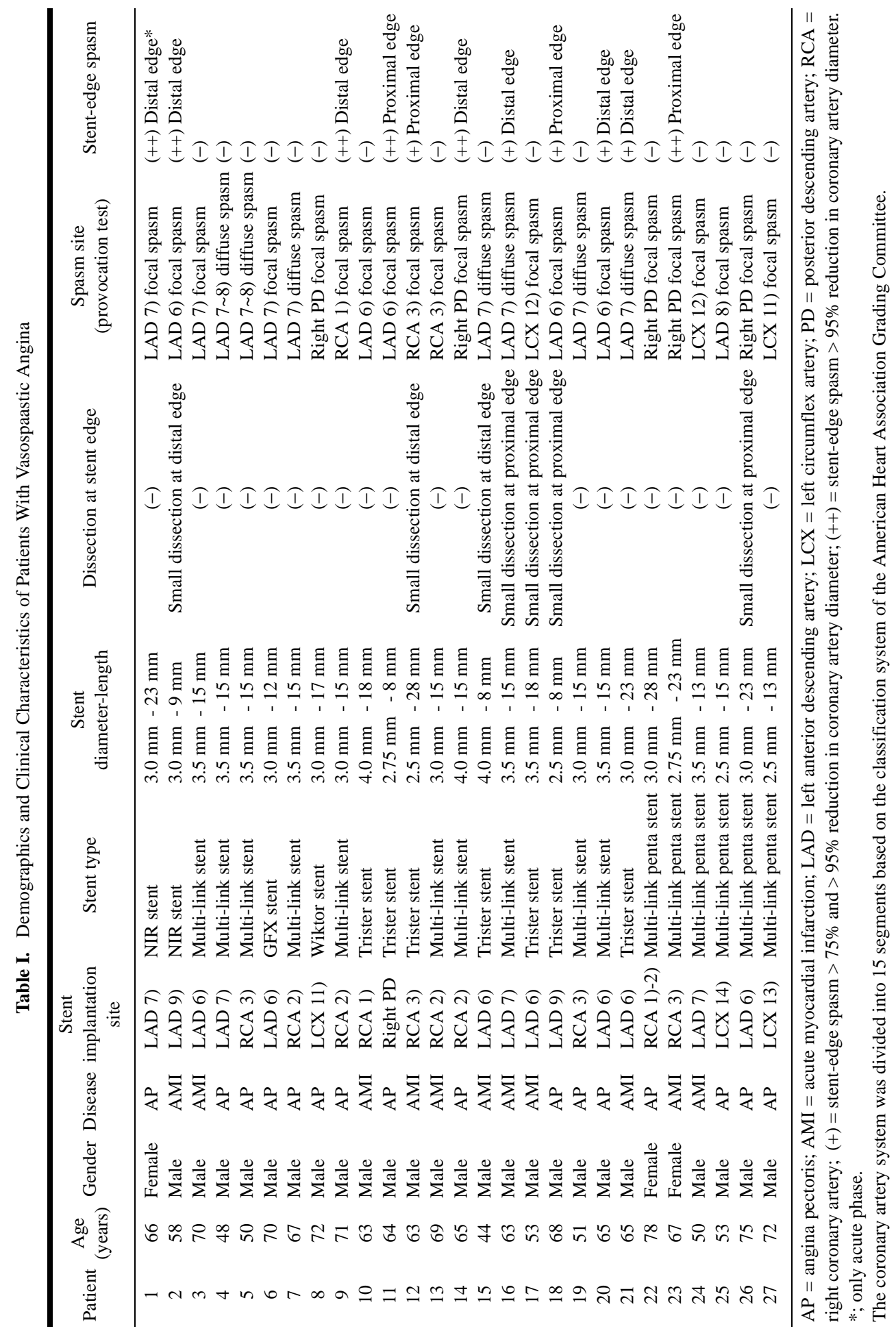




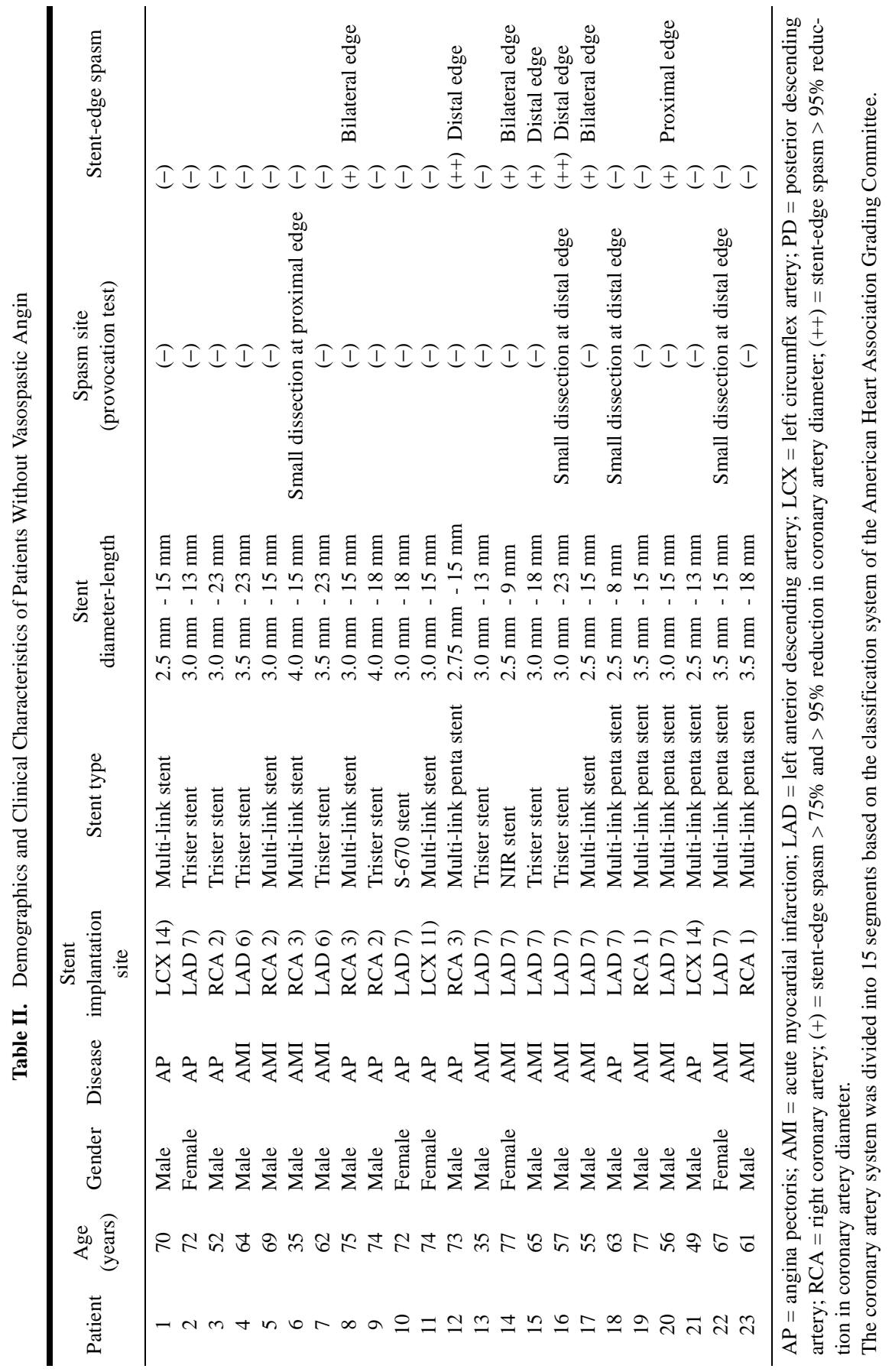


one patient refused to undergo the spasm provocation test at the chronic phase after stent implantation. In the spasm provocation test, acetylcholine was used in 4 patients with VSA and 3 patients without VSA, and ergonovine was used in 21 patients with VSA and 19 patients without VSA. Severe natural stent-edge spasm (> 90\% reduction in coronary artery diameter compared with that after isosorbide dinitrate) was observed in two patients in the control angiography (see the results) and we did not use the spasm inducing drugs in these 2 patients. We could not completely exclude the possibility that an episode of spasm might induce serious cardiac complications, particularly in patients with old myocardial infarction. Therefore, our Hospital Ethics Committee provided the following limitations on our protocol for spasm provocation testing to prevent complications associated with the provocation test:

1) Vasodilating drugs, including calcium channel antagonists such as nisoldipine or nifedipine, nitrates such as isosorbide mononitrate, and other vasodilating substances such as nicorandil were continued until 15 hours prior to the provocation test for coronary spasm in this study. As a result, the drug-free interval before the spasm provocation test was shorter than other studies. ${ }^{11)}$ Long-acting calcium channel antagonists such as amlodipine were not used in our patients.

2) In patients with VSA, during the spasm provocation test, acetylcholine or ergonovine was injected only into the coronary artery in which the coronary stent was implanted and we avoided injecting these drugs into coronary arteries that did not contain the coronary stent.

3) During the spasm provocation test, we performed coronary angiography frequently and when a stent-edge spasm with $>95 \%$ reduction in a coronary artery diameter was found, isosorbide dinitrate was injected immediately into the coronary artery to treat the coronary spasm.

Stent-edge spasm was classified as either moderate spasm $(>75$ and $<95 \%$ reduction in coronary artery diameter compared with that after isosorbide dinitrate) and severe spasm (> 95\% reduction in coronary artery diameter compared with that after isosorbide dinitrate).

Moreover, during the spasm provocation test, we often observed patients with moderate coronary spasm with $>75 \%$ reduction in coronary artery diameter without any symptoms and ischemic electrocardiographic change. Because the interpretation of these patients is difficult, they were excluded from this study. If severe coronary spasm was induced only at the stent edge, we defined this spasm as "stent-induced coronary spasm".

Written informed consent was obtained from all patients. 


\section{Results}

In one patient with VSA (patient number 1), stent-edge spasm and acute thrombosis occurred several hours after stent implantation, despite adequate administration of vasodilating agents. The spasm was resolved by intracoronary injection of $2 \mathrm{mg}$ of nicorandil and $5 \mathrm{mg}$ of isosorbide dinitrate. The in-stent thrombosis was aspirated using the Rescue ${ }^{\mathrm{TM}}$ percutaneous thrombectomy system (Figure 1). The remaining 26 patients with VSA had no complications during or after stent implantation. During the chronic phase $(6.4 \pm 2.0$ months after coronary stent implantation), severe stent-edge spasm was provoked in 5 (19.2\%) of the 26 patients with VSA who underwent spasm provocation testing (Figure 2) and moderate stent-edge spasm was provoked in 5 patients $(19.2 \%)$. In patients without VSA, severe stent-edge spasm was also provoked in 2 patients $(8.7 \%)$ (Figure 3), and moderate stent-edge spasm was provoked in 5 patients $(21.7 \%)$ (Figure 4). In these patients without VSA, coronary spasm was provoked only at the stent edge (Figures 3 and 4). Even more stent-edge spasm with $>90 \%$ reduction in coronary artery diameter compared with that after isosorbide dinitrate was naturally found in control angiography in 2 cases (1 patient with and one without VSA) (Figure 5).

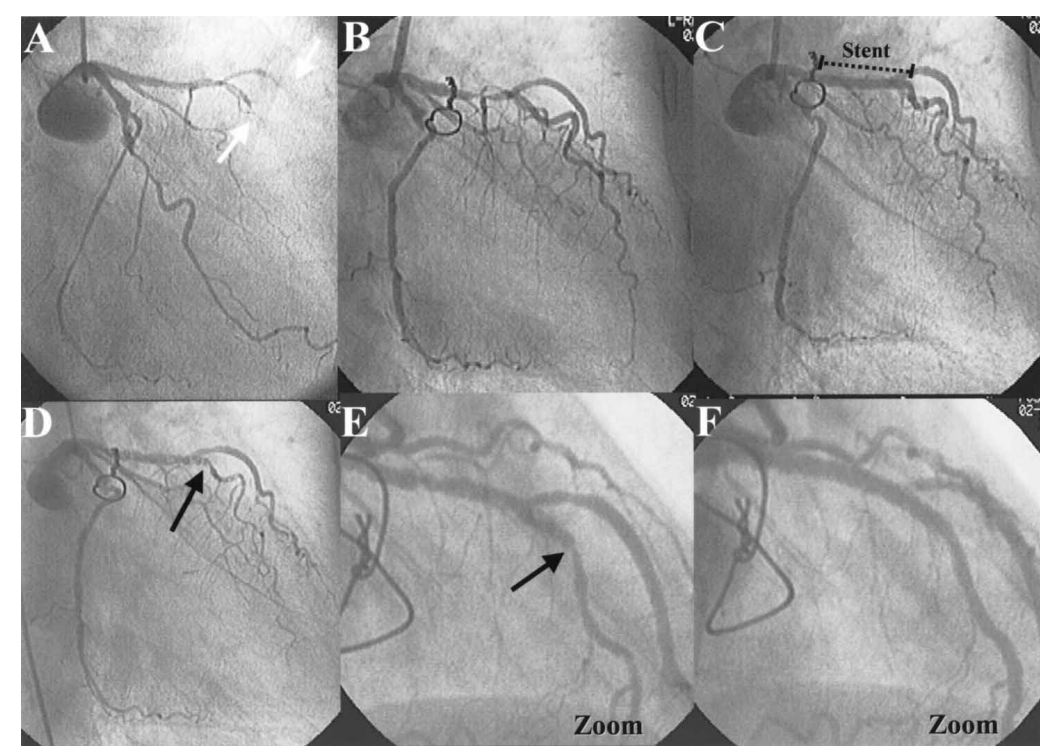

Figure 1. A: Spasm provocation testing 3 years before stent implantation. Severe coronary spasm was induced in the left anterior descending coronary artery (LAD) by intracoronary administration of ergonovine. White arrows denote the spasm site. B: Severe organic stenosis was present in the proximal portion of LAD. C: NIR stent was implanted at the stenotic lesion in the LAD. D: Several hours after stent implantation, severe stent-edge spasm and stent thrombosis occurred. Black arrow denotes the stent-edge spasm site. E: Enlarged view of the stent-edge spasm and stent thrombosis. F: The stent-edge spasm resolved with intracoronary administration of $2 \mathrm{mg}$ of nicorandil and $5 \mathrm{mg}$ of isosorbide dinitrate (ISDN) and the thrombus in the stent was removed using an aspiration catheter. 


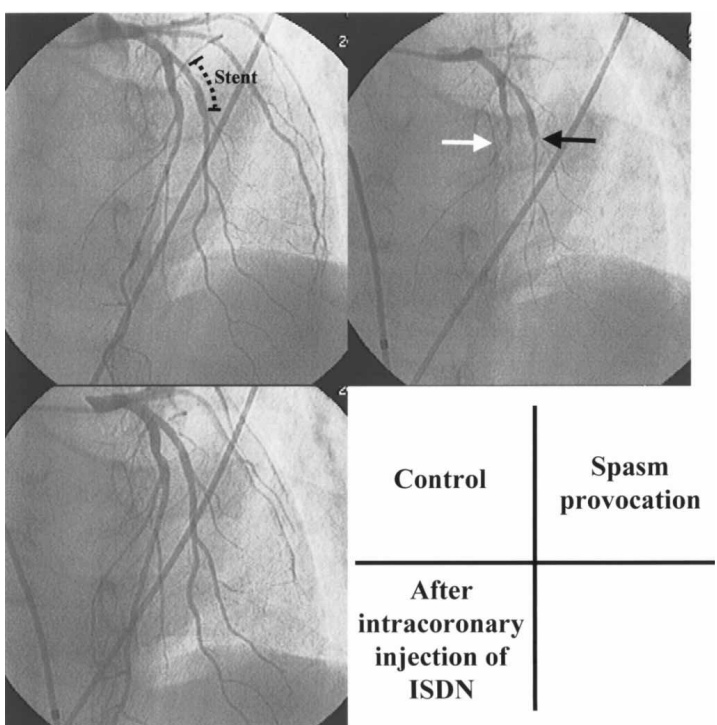

Figure 2. Spasm provocation testing was performed in a patient with vasospastic angina. Severe coronary spasm was induced in the mid-portion of the left anterior descending coronary artery (LAD) and the distal stent edge in the diagonal branch. Both spasms resolved with intracoronary administration of $3 \mathrm{mg}$ of isosorbide dinitrate (ISDN). White arrow denotes the LAD spasm site and black arrow denotes the stent-edge spasm site.

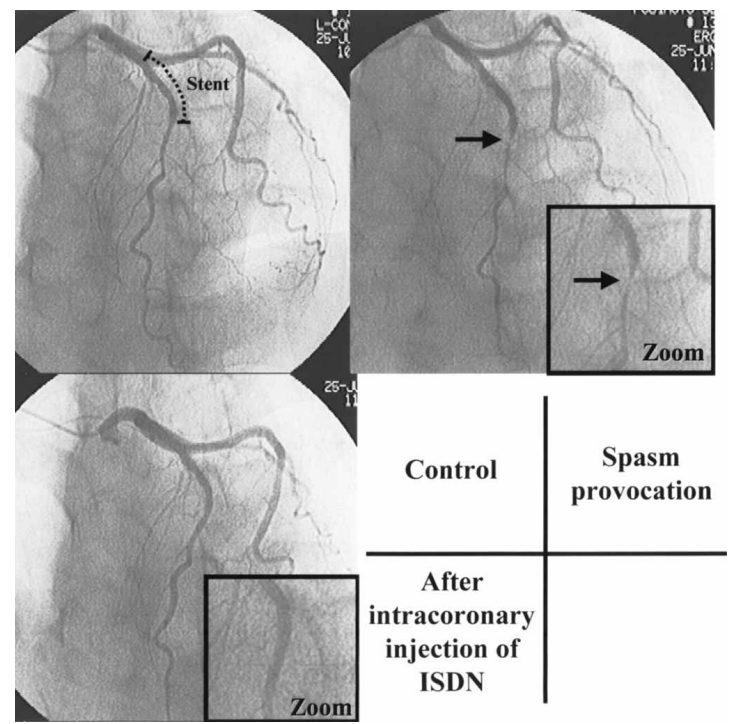

Figure 3. Spasm provocation testing was performed in a patient without vasospastic angina. Severe coronary spasm was induced only at the stent edge. We defined this spasm as "stent-induced coronary spasm". The spasm resolved with intracoronary administration of $3 \mathrm{mg}$ of isosorbide dinitrate (ISDN). Black arrows denote the stent-edge spasm site. 


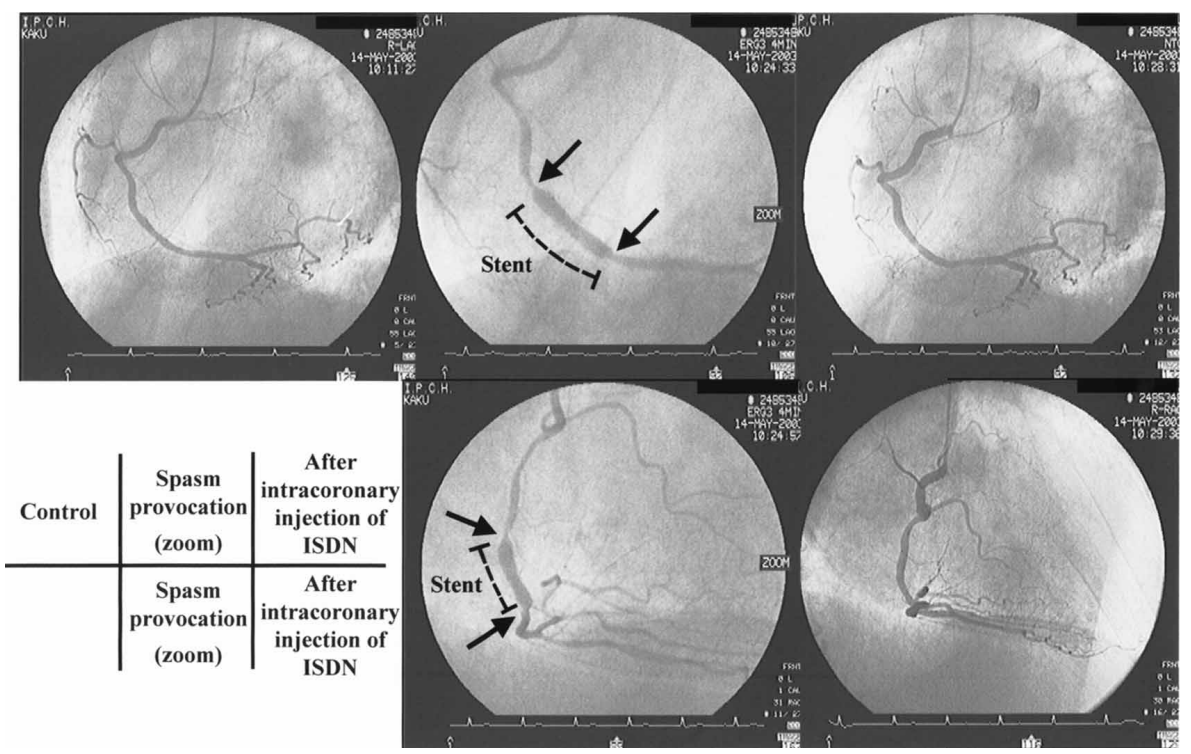

Figure 4. Spasm provocation testing was performed in a patient without vasospastic angina. Moderate coronary spasm was induced only at the bilateral stent edges. The spasm resolved with intracoronary administration of $2 \mathrm{mg}$ of isosorbide dinitrate (ISDN). Black arrows denote the stent-edge spasm site.

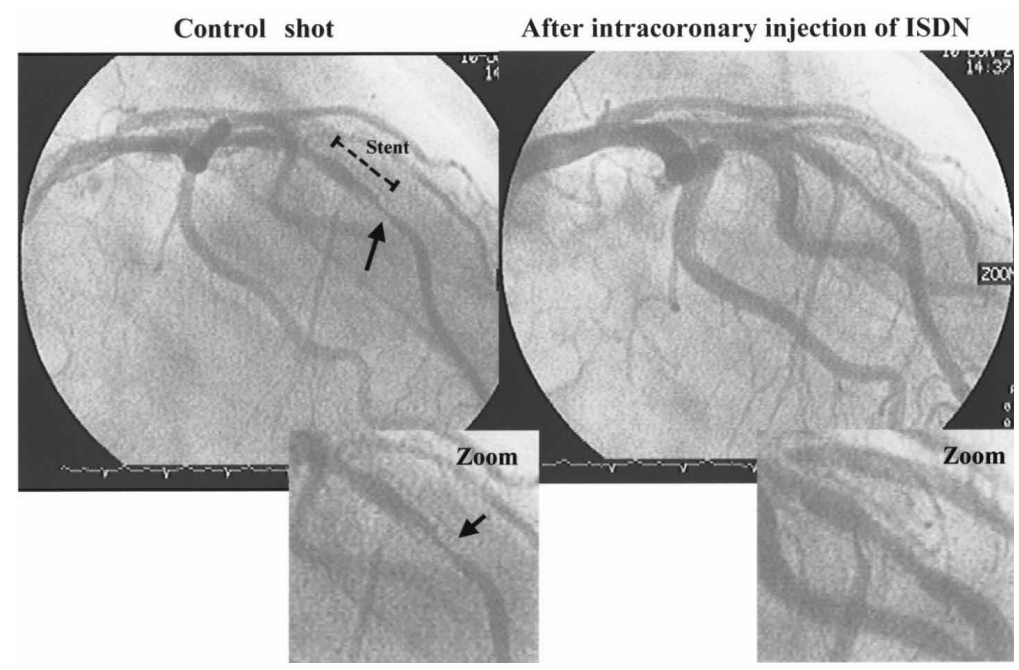

Figure 5. Severe natural stent-edge spasm (> $90 \%$ reduction in coronary artery diameter compared with that after isosorbide dinitrate) was observed in a patient without vasospastic angina in the control angiography. The spasm resolved with intracoronary administration of $3 \mathrm{mg}$ of isosorbide dinitrate. Black arrows denote the stent-edge spasm site. 


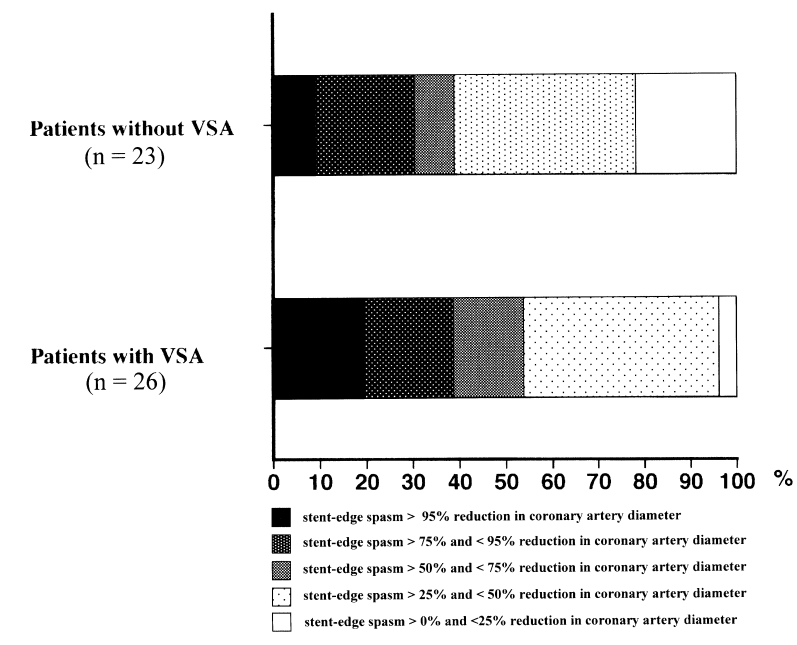

Figure 6. The incidence and intensity of stent-edge spasm in each group.

Between patients with acute myocardial infarction and patients with angina pectoris, the incidences of provoked stent-edge spasms were not different in either VSA or non-VSA group. Additionally, the stent types or small coronary dissections at the stent edges were not related to the incidences of provoked stentedge spasms.

Figure 6 shows the percentages of stent-edge spasm in each group.

\section{DISCUSSION}

Several investigators have reported stent implantation is useful for the treatment of severe coronary spasm that is refractory to adequate medical treatment $^{3-7)}$ and Gaspardone, et $a l^{8)}$ prospectively showed its usefulness in 9 highly selected patients with variant angina refractory to medical treatment. However, it is possible that the stress of coronary angioplasty can alter coronary vasomotor reactivity. For example, with plain old balloon angioplasty, the lesion treated by angioplasty can have enhanced vasospastic activity in response to acetylcholine, even in the chronic phase after intervention. ${ }^{12)}$ In addition, Rodgers, et $a l^{13)} \mathrm{dem}$ onstrated coronary spasm induced by stent implantation in a porcine model. Furthermore, it has been reported that stent implantation induced severe stent-edge spasm in a patient. ${ }^{10)}$ Therefore, it is unclear whether stent implantation is safe in patients with VSA and whether the administration of antivasoconstrictive drugs, such as calcium channel antagonists or nitrates, must be continued after stent implantation. 
In our study, severe stent-edge spasm was provoked in $19.2 \%$ of the patients with VSA, even $6.4 \pm 2.0$ months after coronary stent implantation. If moderate stent-edge spasm was included, stent-edge spasm occurred in about $40 \%$ of these patients. Therefore, it is important to recognize that some patients with VSA may develop new spasm induced by stenting and this spasm might cause new cardiac events if they do not have adequate vasodilating drugs. However, it was surprising that even in patients without VSA, severe coronary spasm was induced at the stent edge in $8.7 \%$ of patients, and if moderate stent-edge spasm was included, stent-edge spasm was observed in about $30.4 \%$ of those patients. In our study, most of the patients without VSA continued to receive vasodilating drugs even several months after stent implantation. Thus, new cardiac events did not occur in all of them. However, after stent implantation, we should monitor the onset of new rest angina or other symptoms of coronary spasm.

The incidence of provoked stent-edge spasm was not different between patients with acute myocardial infarction and patients with angina pectoris. In the early phase (within 14 days of onset) of acute myocardial infarction, coronary spasm in the infarct-related coronary arteries is easily provoked even in patients without VSA. ${ }^{14)}$ However, in our study, spasm provocation testing was performed in the chronic phase (about 6 months from onset) of acute myocardial infarction. We believe this is the reason why the vasoconstrictive response was not different between patients with acute myocardial infarction and patients with angina pectoris.

In our opinion, long-term administration of antivasoconstrictive drugs is necessary in patients with VSA, even after stenting.

When patients without VSA complain of new rest angina, patients with an abnormal vasomotor reaction at the stent edge should be identified. If severe stent-edge spasm is confirmed, long-term administration of antivasoconstrictive drugs might be necessary.

In the present study, all of the patients were Japanese. Other investigators have reported racial differences in the incidence of coronary vasomotor reaction. ${ }^{14,15)}$ According to their reports, in the setting of acute coronary syndrome, the coexistence of coronary spasm is more frequent in Asians than in Caucasians. Therefore, the influence of racial differences should be taken into consideration when discussing the incidence of stent-edge spasm.

Study limitations: It is unclear whether the stent-edge spasm that was induced by the spasm provocation test was related to the natural episodes of ischemic events. However, severe natural stent-edge spasm was observed in control angiography in 2 patients ( 1 patient had VSA and the other did not have VSA). This finding suggests the clinical importance of newly occurring stent-edge spasm. 
The diagnosis of VSA is sometimes difficult because some patients with severe coronary spasm complain of only chest discomfort without typical rest angina or chest pain on effort ${ }^{11)}$ and the disease activity of coronary spasm may be related to the results of spasm provocation testing. ${ }^{16)}$ Therefore, it is very difficult to completely exclude the possibility of a patient having VSA in our patients without VSA.

In conclusion, the results of this study suggest that we should not neglect newly occurring stent-edge spasm in patients either with or without VSA. Longterm administration of vasodilating drugs should be considered in some of these patients even after stent implantation.

\section{REFERENCES}

1. Serruys PW, de Jaegere P, Kiemeneij F, et al. A comparison of balloon-expandable-stent implantation with balloon angioplasty in patients with coronary artery disease. N Engl J Med 1994; 331: 489-95.

2. Fischman DL, Leon MB, Baim DS, et al. A randomized comparison of coronary-stent placement and balloon angioplasty in the treatment of coronary artery disease. N Engl J Med 1994; 331: 496-501.

3. Lopez JA, Angelini P, Leachman DR, Lufschanowski R. Giantruco-Roubin stent placement for variant angina refractory to medical treatment. Cathet Cardiovasc Diagn 1994; 33: 161-5.

4. Kultursay H, Can L, Payzin S, Turkoglu C, Altinting A, Akin M. A rare indication for stenting: persistent coronary artery spasm. Heart Vessels 1996; 11: 165-8. (Review)

5. Nakamura T, Furukawa K, Uchiyama H, Seo Y, Okuda S, Ebizawa T. Stent placement for recurrent vasospastic angina resistant to medical treatment. Cathet Cardiovasc Diagn 1997; 42: 440-3.

6. Jeong MH, Park JC, Rhew JY, et al. Successful management of intractable coronary spasm with a coronary stent. Jpn Circ J 2000; 64: 89-900.

7. Nedeljkovic MA, Ostojic M, Beleslin B. Treatment of medically uncontrolled coronary artery spasm in the normal coronary artery with coronary stenting. J Invasive Cardiol 2002; 14: 633-5.

8. Gaspardone A, Tomai F, Versaci F, et al. Coronary artery stent placement in patients with variant angina refractory to medical treatment. Am J Cardiol 1999; 84: 96-8.

9. Khatri S, Webb JG, Carere RG, Dodek A. Stenting for coronary artery spasm. Catheter Cardiovasc Interv 2002; 56: 16-20.

10. Muroya $\mathrm{T}$, Ohe $\mathrm{H}$, Sakai $\mathrm{H}$, et al. A case in which stent insertion is considered to have triggered contrast medium-induced coronary vasospasm. Jpn Circ J 1999; 63: 315-8.

11. Kaku B, Kanaya H, Horita Y, Uno Y, Yamazaki T, Ohka T. Self-vasodilating ability at the spastic site of patients with vasospastic angina; estimation by acetylcholine delayed phase. Jpn Heart J 2003; 44: 299-311.

12. Kirigaya H, Aizawa Y, Ogasawara K, et al. Incidence of acetylcholine-induced spasm of coronary arteries subjected to balloon angioplasty. Jpn Circ J 1993; 57: 883-90.

13. Rodgers G, Raizner A, Cromeens D, Wright K, Stevens C, Roubin G, Minor S. Coronary spasm induced by stent implantation. J Am Coll Cardiol 1989; 13: 194A.

14. Pristipino C, Beltrame JF, Finocchiaro ML, et al. Major racial differences in coronary constrictor response between Japanese and Caucasians with recent myocardial infarction. Circulation 2000; 101: 1102-8.

15. Sasayama S. How to study the prevalence and mechanisms of racial differences in coronary vasomotor response. Ital Heart J 2002; 3: 237-40. (Review)

16. Maseri A.Variant angina. In : Maseri A, Editor. Ischemic Heart Disease, 1st ed. NewYork: Churchill Livingstone Inc; 1995; 559-88. 